\title{
The Pedagogical Implications of Implementing New Technologies to Enhance Student Engagement and Learning Outcomes
}

\author{
Alison Sammel, Katie Weir, Christopher Klopper \\ School of Education and Professional Studies, Griffith University, Queensland, Australia \\ Email: a.sammel@griffith.edu.au
}

Received September 20 ${ }^{\text {th }}$, 2013; revised October $20^{\text {th }}$, 2013; accepted October $27^{\text {th }}, 2013$

\begin{abstract}
Copyright (C) 2014 Alison Sammel et al. This is an open access article distributed under the Creative Commons Attribution License, which permits unrestricted use, distribution, and reproduction in any medium, provided the original work is properly cited. In accordance of the Creative Commons Attribution License all Copyrights (C) 2014 are reserved for SCIRP and the owner of the intellectual property Alison Sammel et al. All Copyright (C) 2014 are guarded by law and by SCIRP as a guardian.
\end{abstract}

\begin{abstract}
This paper reports the findings of research conducted by three teacher educators about the effects on teaching and learning from implementing a variety of digital technologies in their undergraduate courses. The aim of this study was to assess the degree to which certain university supported digital technologies assisted in promoting student engagement and participation in collaborative learning. The data are based on the semester long experiences of the three lecturers and their students. From this data emerged an holistic picture that highlights which of the implemented digital technologies constrains or enables particular pedagogical aspects such as communication of course requirements; student engagement, meaningful formative feedback; and deep connections between course elements. This picture assisted the authors in generating a matrix for implementing certain digital technologies that cater for diverse learning styles, and diversely experience an interest in using technology. The theoretical framework for building the matrix is based on Collins, Brown and Newman’s (1990) Cognitive Apprenticeship Model. It is also underpinned by the suggestions that as "teachers" we too often overlook whether or not our students have the requisite skills to engage with technologies because of tacit assumptions about how this generation of students wants to learn. Likewise, the same can be said of those who provide professional development sessions for staff who are learning how to use new technologies and who often appear to make similar assumptions.
\end{abstract}

Keywords: Digital Technologies; Online Education; Pre-Service Teacher Education

\section{Introduction}

Walking into any university course in Australia, or indeed around the world, you will find students who have different reasons for attending, different levels of motivation, different attitudes and expectations towards their learning, and different responses to technology. Understanding these differences not only allows teaching staff to better cater to the diverse learning needs of their students, but can also increase student engagement, satisfaction and retention (Felder \& Brent, 2005). Seymour and Hewitt (1997) showed that many of the students who drop out of university courses or programs do so not because they are the weaker students, but because they are not engaged with their learning and feel dissatisfaction with their educational instruction. To advance the reputation of the university, and to increase student retention, efforts to increase student engagement with learning materials and improving student satisfaction with courses have been an important goal within universities for some time (Moosmayer \& Siems, 2012). By reflecting on university courses that students find successful, patterns endorsed by universities emerge. Patterns such as creating supportive places where students can easily and effectively interact with one another, the university teaching staff and the course materials. In these successful courses, high le- vels of student engagement are achieved. Students who are engaged perceive that they learn more, and become more satisfied with the learning experience (Arbaugh, 2008; Boston et al., 2009; Garrison \& Arbaugh, 2007; Garrison \& Cleveland-Innes, 2005; Richardson \& Swan, 2003; Rubin et al., 2013; Swan, 2002). Research has found strong links between successful courses, effective use of technology and student achievement and contentment (Liaw, 2008; Levy, 2008). Specifically, technology used to support university courses can directly affect student satisfaction and success through promoting ease of interaction and understanding of course materials, increase facilitation between students and faculty, improve feedback, and encourage interactive and independent learning (Selim, 2007). For this reason, this study will examine how three academic staff members and their students assess certain digital technologies in the promotion of student engagement, and staff and student satisfaction.

\section{Theoretical Background: Task-Technology Fit}

To gain a greater understanding of the factors that influence technology use, student engagement, and staff and student satisfaction with technology, it is helpful to explore task-technology fit theory. Goodhue and Thompson (1995) suggest that 
in order to have a success outcome with technology usage, the users need to distinguish the goals for task and the fit between the task and the technology. The basic argument of this theory is that for a technology to have a positive impact on outcomes and satisfaction, the technology must fit with the tasks it is supposed to support, and the understandings and needs of those who use it (Rubin et al., 2013). The better the task-technology fit, the more it is anticipated that there will be positive consequences from using the technology. In the context of using various digital technologies within the three university courses being investigated, the academic staff hoped the anticipated consequences included facilitating a clearer understanding of course objectives and assessment items, and promoting a deeper, more engaging and satisfying learning experience. As such, task-technology fit refers to the ability of the various digital technologies to support students in the range of learning activities they engage in, whilst accommodating the variety of student abilities. These activities include promoting ease and comfort communicating with other students and the academic staff, accessing and promoting a deeper understanding of learning materials and encouraging interaction and discussions in lectures and tutorials. McGill \& Klobas (2009) advocate that by increasing awareness and understanding of the relationship between the technology and the needs and goals of its user(s), task-technology fit will have a positive influence on satisfaction.

This theory suggests that for a digital technology to achieve a certain mission, in this case increase student engagement, the technology must first meet the needs of the user. Therefore, the needs and understandings of the user must be explored. This includes attitude and beliefs towards technology use, social norms around the use of technology, prior comfort with technology use, experiences with other form of technology, and any facilitating conditions. Further, technology-task fit also necessitates that there is an understanding of functionality and characteristics of the technology. By addressing both the needs and goals of the users, and the features of the technology, this study explores the factors that influence technology-task fit such as the perceived usefulness of the technology, communication quality and changes in understanding knowledge, as well as staff and student engagement, self-efficacy, computer literacy and situational understandings. All these factors have been shown to influence both the use of technology and their performance impacts.

\section{Research Design and Methodology}

Design-based research (Brown, 1992; Collins, 1992) is an emerging paradigm for the study of learning in contexts through the systematic design and study of instructional strategies and tools. The Design-Based Research Collective (2003) argues that design-based research can assist in the creation and extension of knowledge "about developing, enacting, and sustaining innovative learning environments” (p. 5). There is no single design-based research method, but rather an explicit overarching concern for using methods that link processes of enactment to outcomes. This overarching concern is seen to have the potential to generate knowledge that directly applies to educational practice. "The value of attending to context is not simple that it produces a better understanding of an intervention, but also that it can lead to improved theoretical accounts of teaching and learning” (The Design-Based Research Collective,
2003: p. 7). This approach in which the context and intervention are problematized sets this research method apart from traditional evaluation where the intervention is evaluated against a set of pre-determined standards (Worthenm, Sanders, \& Fitzpatrick, 1996). The intention of design-based research in educational settings is to generate models of successful innovation rather than particular artifacts or programs (Brown \& Campione, 1996).

\section{The Procedure}

The study was conducted in Semester one, 2012 at a large multi-campus university in Queensland. Three academic staff members teaching Science, Assessment and Communication within a School of Education, reflected on the aim, goals and practices of their instruction to understand what they would like to improve upon. Increasing student engagement in lectures, within the online course community and with the course content emerged as the main theme. The three academics worked with their blended learning support team to investigate the different university supported digital technologies that would promote their agenda. Each academic choose a few digital technologies to learn and implement in their Semester one course. During and after the implementation semester, each of the academics wrote a case study explaining their experiences and findings. Portions of these case studies are presented in the data section.

There were a 204 students enrolled in the first year communication course, 151 in the third year science course and 160 students in the forth year assessment course. This gave a total of 515 students who were asked to participate in this study. The students were asked to complete an online survey at the start of semester one. An academic who was not teaching into that specific course gave each cohort of students instructions about how to complete the survey and its importance. Students were told that it was voluntary and anonymous. The online survey asked questions about students' previous experience with technologies in "learning" (etc. classrooms, lectures, tutorials) situations. They were also asked questions about their expectation of face-to-face learning and online means of learning, their expectations of technology and how they prefer to learn. Twenty-seven students participated in the online survey; the results are presented in the data section.

To further explore student how the students engaged with the digital technologies offered in their courses, three focus group interviews were conducted. Each group had around 25 - 30 participating students. The students were asked open-ended questions about the what digital technologies they used in their course; which ones they preferred and why; their motivations, expectations and experiences using the technology; whether the technology improved their learning outcomes; whether it engaged them; challenges and issued encountered and if they had any specific feedback about the digital technologies utilized in their course. These focus group interviews were taped and then transcribed. The results of these interviews are highlighted in the data section.

\section{Exploring the Task and the Technology: Three Case Studies}

\section{The Staff Experience}

Each staff member on the research team produced a case 
study that recorded their experience with implementing new digital technologies with a goal to enhance student engagement and learning in their respective courses. These are presented below with the associated discipline identified in brackets. Each case study was analysed for any recurring or significant themes that were categorised under two subheadings: "Professional Development” (improving their technological skill level) and "Course Implementation" (the outcomes of implementing digital technologies in their respective courses). The findings from these analyses are summarised under these same headings in the right hand column of the Data Summary Table at the end of this section.

\section{Staff Case Studies}

1) Lecturer 1 (Assessing Primary Students’ Learning)

This particular course was chosen to be put under the spotlight of this study because of the low scores and negative feedback in the student experience survey data the previous year. This situation was seen as an opportunity to implement new technologies for enhancing the delivery of the curriculum and for improving communication with students with a goal of enhancing the quality of their learning experience. Apart from the major aspects of the course that were revised such as the assessment items, the technologies I decided to implement this semester included the following: an online assessment submission process (Safe Assign) for greater efficiency and for its capacity to provide better feedback; Lecture Capture to record the lectures that focused on the two assessment tasks; Personal Lecture Capture (Echo360) to ensure consistent delivery of key course messages; and a collaborative online classroom (Wimba) to enhance communication. Other digital technologies in place such as the course website and the online discussion board were also revamped to improve curriculum delivery and course communication.

Once I had selected these new digital technologies I undertook professional development provided by our Technology Advisor. I also undertook further learning about the technologies I was already familiar with e.g., Safe Assign and the Discussion Board where my learning focused on improving their functionality. Wimba was the technology I was least familiar with after experiencing immense frustration trying to access and utilise a Wimba classroom successfully from off-campus I rejected this technology out of fear that students would experience the same access and communication issues. I was similarly unfamiliar with Personal Lecture Capture (Echo360) and this turned out to be another option I rejected because of time constraints and the lack of resources for preparing quality recordings, both technical and human.

I utilized Lecture Capture selectively to record the lecture content directly related to the assessment tasks. Student attendance dwindled to less than half the enrolled number by the final lecture. The tracking data from the university's blackboard site indicate that $80 \%$ of students accessed Lecture Capture.

Using Safe Assign for assignment submission created some unforeseen challenges for online marking. One of the reasons this technology was implemented was for its plagiarism analytics as the assessment task is recycled each year. Safe Assign allows only one file to be submitted which created issues for students who had saved their task in different formats and in different documents (despite explicit instructions requesting their submission as one Word document). For the course teaching staff this method of providing feedback to students "in situ" using the "Track Changes" function was preferred over tradi- tional handwritten comments on paper-based assignments but if students saved their files in other formats they were prevented from providing this sort of targeted and feedback on their work. How students named their files was problematic and it was time consuming to remediate this by re-naming each file. The download function in Safe Assign did not work off-campus, which was another glitch in the system especially when the sessional staff were already under confident with using this online assessment system. More problems emerged when assignments were returned, as it was not clear to students how to access their marked work. None of these sorts of pragmatic issues were addressed in the PD sessions I attended but now I am aware of them they can be easily remediated with appropriate and explicit instruction for staff and students.

The Discussion Board was utilised more around the due dates for assessment and the focus of the discussions was purely on details regarding the assessment tasks.

2) Lecturer 2 (Primary Science Education)

The course I chose to investigate was a primary science course. My goal was to implement a range of digital technologies that I had not used before and to investigate what I found to be practical and useful, and to explore how the students responded to each of them. This course was the second core science course the Bachelor of Education (Primary) students needed to take. It runs in the first semester of their third of four years. There were 151 students ranging in age from school leavers to mature age students. Attendance at the lectures was nearly $100 \%$ at the start but on average became around $70 \%$ of the student cohort.

The first digital technology initiative I implemented was Echo360 which I used to record detailed explanations of the assessment tasks. I went through both the assessment outline and the corresponding marking rubric. I wanted to ensure that my students had a consistent and clear message around their assessment items. Each recording was around 11 minutes long and consisted of specific details and helpful tips and advice. I used prior student examples displayed on the computer screen to address major aspects of the assessment task. The students commented that they appreciated this information; especially the verbal explanations using prior students work to demonstrate my point. They said this assisted them in undertaking the assessment task. However, in response to further questioning, the majority of students tended to focus on the practical examples provided rather than also seeking to understanding how their work would be evaluated using the rubric. This lead to students forgetting to do certain small tasks, like correctly referencing. The student tended to not access the assessment information at the start of the course but when it was needed. There were quite a few students who came to me for assessment advice and when asked if they had listened to the specific Echo360 recordings under assessment at the Learning at Griffith site, said they had forgotten about it. These were students who did attend the lectures but usually arrived late, hence missing the verbal reminder to access these recordings, however a reminder was usually written on the white board in the lectures. I would have liked the tutors to have used and promoted using the Echo360 recordings more. This could have been done by listening to it themselves or directing students to listen to it when they had assessment questions, or displaying it on the whiteboard when answering specific questions. Some of the four tutors gave assessment information that was different to what was in my recordings, leading to confusion amongst the 
students. As this was a new tool to this course, I found tutors and students were not in the habit of listening to the assessment recording, and so did not use it as the supportive tool that it was intended to be.

Lecture Capture was also implemented in this course to record each of my nine, 2-hour lectures which were then uploaded into the relevant weekly folder on the course Blackboard site within 24 hours of each lecture. An announcement was also circulated to the students when this lecture material was available. The students could access the lecture content through Lecture Capture whenever they chose to. Statistical tracking showed the majority of students listened to all nine recordings, but not within a week of the given lecture, rather around the week before their end of the course exam. When asked, the students who regularly attended lectures explained that it was only if they had missed the lecture or did not understand a point, would they listen to the recorded 2-hour lecture within a week of the lecture. The majority said that this tool was an important part of their exam study process as they would re-listen to specific lectures that they found the content more difficult to study. Rarely did the students listen to all recorded lectures, but nearly each student explained they would listen to 2 or more recordings out of the nine. There was no specific pattern to their relistening, however, the chemistry and physics lectures were mostly replayed.

The formal university course and teaching evaluations allowed only for comments around the Lecture Capture aspect of the course. It showed there was a mixed reaction to this tool. When asked if the recorded lectures assisted their learning, on a scale of low, medium, high and neutral, $30 \%$ of the student responded with the "high", while $40 \%$ replied with a "medium" response and the final 30\% identified as "neutral". There were no written comments relating to any of the digital technology implementations. These mixed reviews may have been due to the fact that students could not specifically skip to certain points in the recording and did not want to re-listen to the whole of the 2-hour lecture. New Lecture Capture programs now allow for movement to specific places in the recording, and statistical tracking in my more recent courses have shown students are accessing Lecture Capture more frequently. Another reason for the mixed reviews may involve my interactive lecturing method, which involves many student-centered activities that Lecture Capture cannot fully record. The visual and sound quality for these student based experiments and activities would not have been at the same high level as when I was talking to the specific PowerPoint images on the screen. To this end, the Lecture Capture capabilities only really support a "chalk and talk" style of lecture, and not the process of interactive demonstrations, activities or discussions that allow for the joint development of knowledge. To this end, Lecture Capture does not translate well for my lectures. However, students do have the potential to access what information is recorded at any time.

The third digital technology initiative I implemented was JPoll. JPoll supported my desire for more interactive pedagogy as it enables students to anonymously articulate their prior knowledge of a science topic and displays the collective results. These results initiate discussions around science content and pedagogical strategies related to teaching that science topic. I used this technology to replace a more general PowerPoint discussion of key alternative conceptions primary aged students have about science topics. JPoll allowed me to interactively investigated science misconceptions. To assist students' use of the tool I developed a slide to explain what JPoll was, how to connect to the university's wireless Internet, and then connect to the JPoll site. Any student with a smart phone or mobile computer device could access JPoll. Those students who did not have a computer or a smart phone completed the task in pairs or groups with students who did have this technology (about $50 \%$ of students). This organisation process involved developing 15 true or false questions before the lecture. The answers the students provided to the 15 questions were anonymous, thus no individual student answer could be identified. Once answers are entered into a mobile device, the statistical information instantaneously displays on the front screen. This instant, visual statistical information dramatically highlights any science inconsistencies student have without revealing individual responses. This resulted increased engagement, promoting deeper discussions compared with previous years. I displayed the information in a bar graph of either true or false, so everyone could quickly see what percentage of the students thought the question to be either true or false. From this information a large group discussion was started. When asked about the experience of using this technology to promote engagement and learning, the students were full of praise for every aspect of this process. No one complained that it was not individually accessible, as they did not have the smart device available to them personally. I assumed this would be more of a problem. I believe JPoll worked well, however instead of only having access to questions formulated before the lecture, it would be advantageous to be able to type in questions during the lecture. Being limited to only using re-registered questions I found a bit restrictive for my preferred pedagogical style.

Implementing these three learning technologies was rewarding for enhancing my science pedagogy and allowed me to model using these technologies for pre-service teachers.

3) Lecturer 3 (Primary Music Education)

The course was implemented according to the University's mandatory three hours per week (one hour lecture and two hour tutorial) model of delivery, with a further seven hours expectation allocated for course related self-study. The lectures were designed to present the theoretical content through transmission mode while the tutorials provided avenues for interactive practical application of the lecture material. The Blackboard course site was identified as the platform best suited to harness the potential of a range of instructional delivery technologies to augment best features of face-to-face interaction. On the site course content was offered from the beginning of the semester in weekly folders consisting of lecture notes; lecture PowerPoint slides, and recommended readings. Each lecture was captured weekly using Lecture Capture operating system and uploaded to the course site within ten minutes of the lecture concluding. This allowed students to repeatedly access the lecture asynchronously for further engagement, reflection, and clarification. It also afforded absent students access to the lecture presentation.

I used an assessment Vodcast provided explanations of the text-based assessment task which proved valuable in offering a consistent explanation of assessment expectations, which both students and sessional teaching staff could refer to throughout the semester.

The virtual learning environment, Wimba classroom, was opened for synchronous interaction five times during the semester of 50 minutes duration. This occurred after an overview of 
operation was presented during the tutorial of week one. Further text-based support materials were provided on Blackboard site to guide the student through installing and running the Wimba Wizard on their personal computers. The intention of the Wimba classroom was to assist students to undertake the written task successfully through support offered via alternate ways. Sessions focused on academic writing skills, unpacking the task, making sense of the prescribed readings and writing the essay. The centrality of critical thinking underscored the sessions. While this virtual learning environment offered synchronous interaction it was decided to archive all the sessions to allow asynchronous membership. This proved valuable for students who were unable to actively participate during synchronous availability.

Other resources uploaded to the Blackboard site include exemplars of learning materials for music classrooms, suggested further readings, tips and hints for assessment tasks, and shared findings where students could upload resources suitable for the teaching of music education in the primary school. As part of the written assessment task, students were required to evaluate one of these resources. To this end, www.artsmmadd.com was provided as an open source content webpage for use.

Remote assignment submission was selected to reinforce the use of ICTs within this course. This submission mechanism allowed students to submit their assignment remotely from an off-campus location.

A representation of access by source is presented in the diagram below. It does not argue for any one source to be better or superior to another, but rather provides the backdrop to discuss the potential of each source to support the achievement of the learning outcomes through scaffold learning, as shown in Figure 1.

Not surprisingly the Course Content received the highest access. As lectures were the principal mode of content delivery the $84 \%$ access of source suggests the importance and value that students place on having access to the course content. In the attempt to revamp the instructional delivery technologies (IDT) with this course to cater for the 'new' learner by integrating IDTs into the classroom, I expected a much higher access percentage associated with the Lecture Capture and Wimba sources. I can rationalize the low access rate of $55 \%$ for Lecture Capture through the high attendance rate of lectures, but initially I could not fathom the low access rate of $10.9 \%$ for the Wimba session. This required a closer examination.

Few students could grasp how to access the Wimba virtual learning environment. Many spoke of the difficulties experienced trying to access Wimba from an off-campus location. I recall during the first week of the semester having three students arrive at my office and ask: "Where is the Wimba classroom? You have not advertised the location." I naively thought that this was just the sentiment of a few students, but learned that I was wrong. My assumption and expectation of a generation whom have been exposed since birth to the Internet and hypertext to think and process information differently from previous generations was inaccurate. Advances in teaching and learning come through evolution not revolution. I realized that the students required scaffold learning to access and use the learning technologies effectively to enhance their learning outcomes in this course.

\section{Student Experience}

The following results are drawn from an analysis of three data sources. The first is from an online survey that students voluntarily completed at the beginning of the course. The survey contained a mix of closed and open questions that asked for students' opinions and comments on their prior learning experiences at university as well as their expectations about learning in higher education. The second data source was a series of focus group interviews conducted at the end of the course. During these sessions students were asked a series of openended questions designed to gather feedback on their experience with the digital technologies employed in each course. A thematic analysis of the data was conducted and these results are described in detail below and summarised in the first two columns of the data summary table at the end of this section. The third and final data source was the formal university course and teaching evaluation surveys (or student experience surveys) to which the authors added an open question that asked students to provide feedback on the employment of digital technologies in each course. The response to these surveys was poor and nature of the responses was of limited use and so it is omitted from the Data Summary Table that gives an overview of the findings from the combined data sources.

1) Survey data: Students Prior Learning Experiences

The quantitative survey data regarding students' experiences

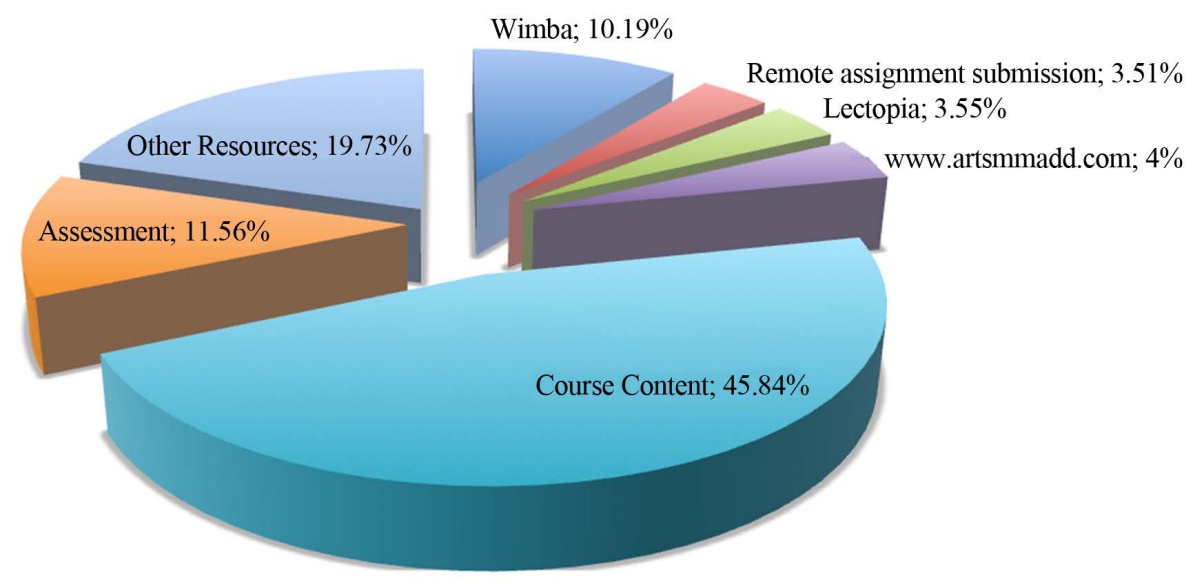

Figure 1.

Representation of access by source. 
with online learning indicates that a significant majority (>75\%) of the students surveyed had previous experience with accessing resources and other learning materials from the internet, viewing PowerPoint presentations, participating in discussion boards. A slightly smaller majority (65\%) had experienced some form of assessment online, while less than half had experience with Wikis or audio-visual lecture-capture. Only two students provided information about "other" online learning experiences they had with Wimba and with Library-referencing.

When students spoke of their lecture experiences some key themes emerged from the survey data. The first theme described lectures in terms of a traditional mode of information delivery that is teacher-centered. This is manifest in phrases such as "a lot of chalk and talk", being "talked at", "listening”, "note-taking” and, "little interaction”. A number of students mentioned PowerPoint presentations as a common AV aid for lectures that focused on theory and whose goal was to present "as much information as possible". Some students did ascribe positive attributes to lectures/lecturers claiming they enjoyed listening to an expert who could provide alternative perspectives to the recommended readings and these students tended to seek motivation to learn more and get some direction to attend to further study.

When students explain how they expect learning to occur in lectures and tutorials a significant number stated that lecturers should be an "expert" and see their role as providing the essence of each week's lecture topic in an interesting and engaging manner. They generally desire more interaction between the speaker and the audience. They expect the lecturer to have ongoing communication with tutorial staff so the delivery of key curriculum messages is consistent. Students clearly distinguish tutorials from lectures as they describe more discussion and interaction with tutors and peers taking place in tutorials. The expected role of the tutor is to create a supportive learning environment where students can ask questions and bounce ideas around to clarify their interpretation and gain a deeper understanding of the course content. Students also mentioned tutorials as places to network with other students. They expect their tutors to have deep knowledge of the subject matter.

When asked more specific questions about the use of technology in lectures and tutorials students stressed the importance of teaching staff having the confidence and know-how to use technology effectively and in appropriate/relevant ways. They also identified audio-visual aids in lectures as assisting in meaning-making by complimenting or elaborating upon any written or print-based text. They would prefer a variety of different technologies be employed as they also identified their use in catering for diverse learning styles. Apart from the Discussion Board, few students mentioned using other technology to communicate with staff whilst social media (such as Facebook) was the preferred contact with other students to discuss more general aspects about the course delivery and content. Nearly all students commented that quality technology was vital for them to access resources and information. Other students made indirect reference to wanting easy access to information and resources through the organisation of the course content.

2) Focus Group Interviews: Students Learning Experiences Post Implementation of New learning Technologies

Three focus group interviews were conducted with students and the responses from both groups were similarly positive about the employment of digital technologies in the courses involved in the study. However one group claimed a persistent preference for traditional modes of teaching and learning through personal communication in face-to-face contexts with print-based materials. All students interviewed agreed that the technology employed did cater for different learning styles. During one focus group discussion many of the students declared their only prior experience with online engagement had been through social media platforms. These platforms are dynamic and interactive and hold appeal for students. These same students expressed that the design of learning technologies promoted at Griffith University to be linear, static, and not particularly interactive.

The most significant finding from both group interviews is a preference for three types of ICTs-Lecture Capture, Echo360 and the Discussion Board due to their ease of access and use, and the assistance to learning they provide. There were different reasons cited for using each of these technologies and the number of times they were accessed also differed. For instance Lecture Capture was claimed to beneficial for clarifying content interpretation and how ideas linked together although students tended to access this only if they missed the lecture or if the lecture focused on the upcoming assessment. The Discussion Board was predominantly used to communicate with their peers and teaching staff to pursue alternative perspectives and clarify instructions around assessment. Students claimed they preferred the Discussion Board for asking for asking questions because it allowed anonymity in the sense that they were "faceless" in a cohort where students were not that familiar with each other (compared with a tutorial where, over time, students became more familiar with others in the cohort). Students reported that they also accessed an unofficial Facebook site for the course where they could communicate between themselves about aspects of the course and help each other to clarify things in their own language.

All students claimed regular and easy access to the university's learning platform. They also all claimed preference for a course sites that are well organised in terms course content. For example they benefited from course content being arranged into weekly folders that contained the required weekly readings plus a selection of optional learning resources. Students indicated that this arrangement was appreciated as saved them a lot of library and database search time with one student commenting that this layout enabled him to "pinpoint the learning outcomes for each week and tie all of the resources together". However all students agreed that they still needed the weekly tutorial sessions to further tie the content together and align it with the assessment requirements. Students claimed they were more motivated to engage with these resources because the lecturer selected them and therefore they assumed these resources were directly aligned with the course learning objectives.

The online assessment processes were well received with few students reporting difficulties uploading their assignments. There was a generally positive response to the SafeAssign reporting feedback as this highlights where they could improve their referencing and it meant they felt "more accountable" for their citation skills. It also meant they could submit a draft attempt and have the time ( 24 hours) to reflect and revise before they could re-upload their final document. The interview data revealed that students appreciated receiving assignment feedback from their tutor/marker online as it was easier to read (when the Track Changes function was utilised land further- 
more, it was retrievable to reflect on when they were completing other assignment in the future.

3) The SEC and SET feedback data

The limited data received from one open question in these surveys supports the focus group interview data with students claiming the technology employed assisted their learning, specifically mentioning Lecture Capture and the organisation of course content material on the course websites. A number of students suggested all lectures should be recorded but this strategy should not replace face-to-face lectures. For the data summary please see Table 1.

\section{Implications for the School of Education and Professional Studies and Initial Teacher Education}

The data obtained from the students and staff who participated in this research project has pedagogical implications for employing digital learning technologies in higher education. We believe the findings are not limited to teacher education and can be generalized for consideration in other higher education contexts. Therefore the conclusions that we draw from our research can assist other most lecturers who are considering using any of these technologies targeted in our research to enhance their course learning outcomes. Conducting the initial survey on student experiences and expectations with learning in higher education was a prudent move as the findings from this data source indicate that we cannot assume that students are motivated by, or know how to use or access the digital technologies we intend to employ in our courses. The fact that a number of students still have a preference for face-to-face communication with teaching staff suggests that we need to be more explicit about our rationale for employing digital technologies and how they will assist and enhance student learning. This finding further highlights the need for staff to be mindful of the diverse learning styles amongst our student cohorts and to demonstrate how a variety of digital and traditional pedagogical strategies can cater for this diversity.

Our findings show that consideration of the diversity of prior experience and knowledge about digital learning technologies amongst the teaching staff is also paramount if they are being used to enhance course learning outcomes. The data from the case studies show that even though the staff were motivated to undertake relevant professional development for each new digital technology, the pedagogy experienced in these sessions did not necessarily assist in employing the technology in a range of learning contexts. The data tells us that direct instruction in a one-hour timeslot about how to use the technology was not enough for staff to understand the complexities and challenges that can arise once students engage with them. A more helpful approach would be to include some discussions about the sorts of problems that can and have emerged when employing new technologies and how to overcome these. The findings from the staff case studies also point to how essential it is to determine the skill level of sessional staff employed to tutor students and to make available timely professional development for these people. If this is not done our results suggest that attempts to enhance course learning outcomes will be undermined by inconsistent or incompetent use of the technology by our sessional staff. Students expect all teaching staff to be competent and efficient users of technology and yet the burden of up skilling in this area is on individual staff members who may not neces- sarily be rewarded (through workload considerations) or remunerated (in the case of sessional staff) for doing so.

Another significant finding that relates to those outlined above is the need to explicitly teach students how to use digital technologies to enhance their learning in addition to explaining why and for what purpose they are being utilised. While all students were comfortable with using the Blackboard learning platform to access course content, there were varying degrees of access and efficient use of Lecture Capture, the Discussion Board and online assessment handling. While we acknowledge that students have to access these tools in order to complete their courses successfully, our research provides evidence that explicitly teaching students the learning benefits of these tools and explaining the different ways they can be utilised should ensure better course delivery and outcomes. For example, it was revealing for staff to discover that students use assignment feedback provided online for assisting them to complete future assignments in the same and other courses. This example alone demonstrates the importance in finding out the variety of ways this and other digital learning tools are utilised by our endusers.

Wimba proved to be the most problematic for students to access and for one staff member the frustration experienced with this learning tool meant it was scrapped before the course commenced. Another concern for staff that emerged from this research was student preference for social media sites such as Twitter and Facebook to have "sideline" discussions about specific courses and staff members. Rather than seeing this as a threat that might undermine our course communication via say, the Discussion Board, we interpret this preference as something which staff can capitalize on. For instance one staff member circumvented any problems this may cause by setting up a course Facebook site and monitoring the discussions thus preventing the misinformation that can circulate between students on these sites.

The research findings outlined above give us some insight into how students and staff experienced the employment of some digital learning technologies in teacher education courses at Griffith University. Even if these results are nuanced and varied depending on staff and student skill level, experience and motivation, we believe they can be used to assist other university staff intending to enhance their course learning outcomes through utilising digital learning technologies. However in its current format our research findings are not easily translated into assisting associated pedagogical strategies in other higher learning contexts. This understanding led us to search for a model of learning into which we could input our findings and enable them to be generalized for broader use. The most appropriate model uncovered for teaching with digital technologies that caters for diverse learning styles and experience in using technologies is the Cognitive Apprenticeship Model developed by Collins, Brown and Newman (1990). Based in constructivist approaches to human learning and situated learning theory (Brown, Collins, \& Duguid, 1989), the model explains how skills are more readily acquired in authentic learning contexts and by communicating with experts and others. The model is also underpinned by the notion that teachers (as "experts") often fail to take into account implicit processes involved in carrying our complex skills when they are teaching novices. In other words, we too often overlook whether or not our students have the requisite skills to engage with technologies that we presume to be relatively simple because we have already 
Table 1.

Data summary table.

\begin{tabular}{|c|c|c|}
\hline Student Expectations & Student Experience & Staff Experience \\
\hline $\begin{array}{l}\text { In lectures and of the lecturer's role } \\
\text { - an "expert" whose role is to capture the } \\
\text { essence of the topic in an interesting } \\
\text { and engaging manner } \\
\text { students desire more interaction } \\
\text { between lecturer and the audience } \\
\text { In tutorials and the tutor's role } \\
\text { - creatinga supportive learning e } \\
\text { nvironment where students can ask } \\
\text { questions and bounce ideas around to } \\
\text { clarify their interpretation of the } \\
\text { course content in an effort to gain } \\
\text { a deeper understanding. } \\
\text { expect their tutors to have deep } \\
\text { knowledge of the subject matter } \\
\text { key learning activity should } \\
\text { involve substantive conversations } \\
\text { between all participants } \\
\text { Of digital learning technologies } \\
\text { - teaching staff need to be confident } \\
\text { and use the technology in appropriate } \\
\text { and relevant ways } \\
\text { expect audio-visual aids in lectures to } \\
\text { assist meaning-making by } \\
\text { complimenting or elaborating } \\
\text { upon any written or print-based resource } \\
\text { prefer a variety of different technologies } \\
\text { recognise their role in catering } \\
\text { for diverse learning styles } \\
\text { communicate with staff and peers } \\
\text { through Discussion Board } \\
\text { social media is the preferred contact } \\
\text { point with peers } \\
\text { quality technology is vital for } \\
\text { them to access resources } \\
\text { and information }\end{array}$ & $\begin{array}{l}\text { With digital learning technologies } \\
\text { - } \quad \text { positive about some digital technologies } \\
\text { but a significant number claimed preference } \\
\text { for campus-based learning that } \\
\text { involves personal communication } \\
\text { and some print-based resources } \\
\text { the technologies employed did } \\
\text { cater for different learning styles } \\
\text { - a clear preference for technologies } \\
\text { with ease of access and assistance to learning } \\
\text { - Echo360 clarified expectations of } \\
\text { assessment tasks } \\
\text { - Lecture Capture was beneficial } \\
\text { for clarifying how ideas linked together } \\
\text { Discussion board predominantly used to } \\
\text { communicate with peers and teaching } \\
\text { staff to pursue alternative perspectives } \\
\text { on ideas and clarify instructions around, } \\
\text { and requirements of the assessment tasks } \\
\text { comfortable with the anonymity of the } \\
\text { Discussion Board when asking questions } \\
\text { (described as "faceless" in a cohort } \\
\text { not all students are familiar with names) } \\
\text { significant number of students also } \\
\text { accessed the “unofficial” Facebook site } \\
\text { for courses where they could communicate } \\
\text { between themselves about aspects of } \\
\text { the course in their own language } \\
\text { organisation of Blackboard sites is important } \\
\text { for tying the lecture content to the tutorial } \\
\text { activity and other learning resources. This } \\
\text { appears to differ widely across courses } \\
\text { but there is a preference for course } \\
\text { content to be well organised } \\
\text { positive about uploading required readings } \\
\text { and other relevant learning materials to } \\
\text { Blackboard. This saved time and } \\
\text { students" assume direct alignment } \\
\text { with learning objectives } \\
\text { online assessment process well received } \\
\text { especially in terms of submission on due dates } \\
\text { positive response to SafeAssign reports that } \\
\text { provide feedback on where students could } \\
\text { improve their referencing-made them feel } \\
\text { "more accountable” for their citation skills } \\
\text { appreciated receiving online feedback which } \\
\text { was easier to read and retrievable for reflection } \\
\text { when completing future assignments }\end{array}$ & 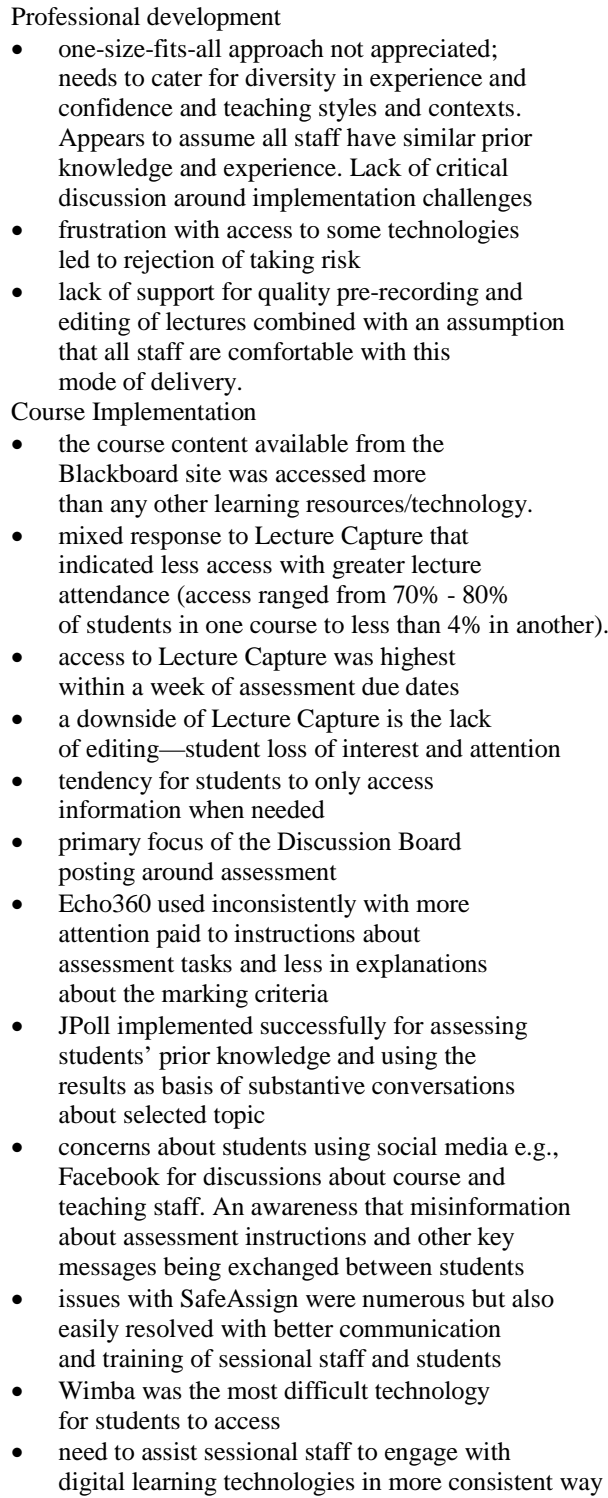 \\
\hline
\end{tabular}

mastered these skills. Likewise, the same can be said of those who provide professional development sessions for staff who are learning how to use new technologies and who often appear to make similar assumptions.

The cognitive apprenticeship model involves a series of pedagogical strategies that run from a highly teacher-centered approach to enabling full student direction over the learning. Running parallel to these pedagogical processes are three stages of learning: from cognitive to associate to autonomous cognition. The model is illustrated in Table 2.

This diagram indicates the cognitive apprenticeship model to be a linear series of teaching processes associated with the three stages of cognition/learning. However, our results indicate that in reality both the teaching and learning involved in utilising new technologies is not static and instead may shift between processes and stages in a dynamic way depending on the experience, motivation and disposition of the teacher and the learner. What makes the model useful is its ability to associate the most appropriate instructional delivery technology with the cognitive stage of the learner. In order for the model to be used successfully, the learner must have an opportunity to articulate where they believe they are along the scale of cognition and so teachers need to provide this opportunity, preferably at the commencement of the course or before the introduction of the delivery technology. This can be done by simply determining prior knowledge and experience with different learning tools and monitoring use and access of the tools as the course progresses.

Based on our experience detailed in the results of this study, we have nominated particular instructional delivery technologies which best suit the cognitive stage of the student. This 
nomination has formulated the instructional delivery technology matrix and but this is not to suggest that this is representative of all possible available technologies. It is proposed that the further development of the matrix be organic depending on learning context. Each instructional delivery technology in the matrix has a hyperlink, which provides a detailed teachers guide for use to enhance student learning (Please see Table 3).

\section{Conclusion}

This study examined the effects on teaching and learning for three academic staff members and their students from integrating of a variety of digital technologies into their university teaching and learning activities. Goodhue and Thompson (1995) suggest that in order to have a successful outcome with technology usage, the user(s) need to distinguish the goals for task and the fit between the task and the technology. With this in mind, both the staff and the students involved in this study were asked to reflect on their goals and expectations around digital technologies, the degree to which the technology supported the task asked of it, changes in student engagement within the university course, and levels of satisfaction with technology. If technology is going to have a positive impact on outcomes and satisfaction, then the technology must first meet the needs of the user. Therefore, this study focused on exploring the needs and understandings of the user(s) including attitude and beliefs towards technology use, social norms around the use of technology, prior comfort with technology use, experiences with other form of technology, and any facilitating conditions.

Our findings showed diversity of assumptions, prior experience and knowledge about digital learning technologies amongst the teaching staff and students. The data from the case studies showed that even though the staff were willing to undertake relevant professional development for each new digital

Table 2.

Three stages of learning from cognitive to associate to autonomous cognition.

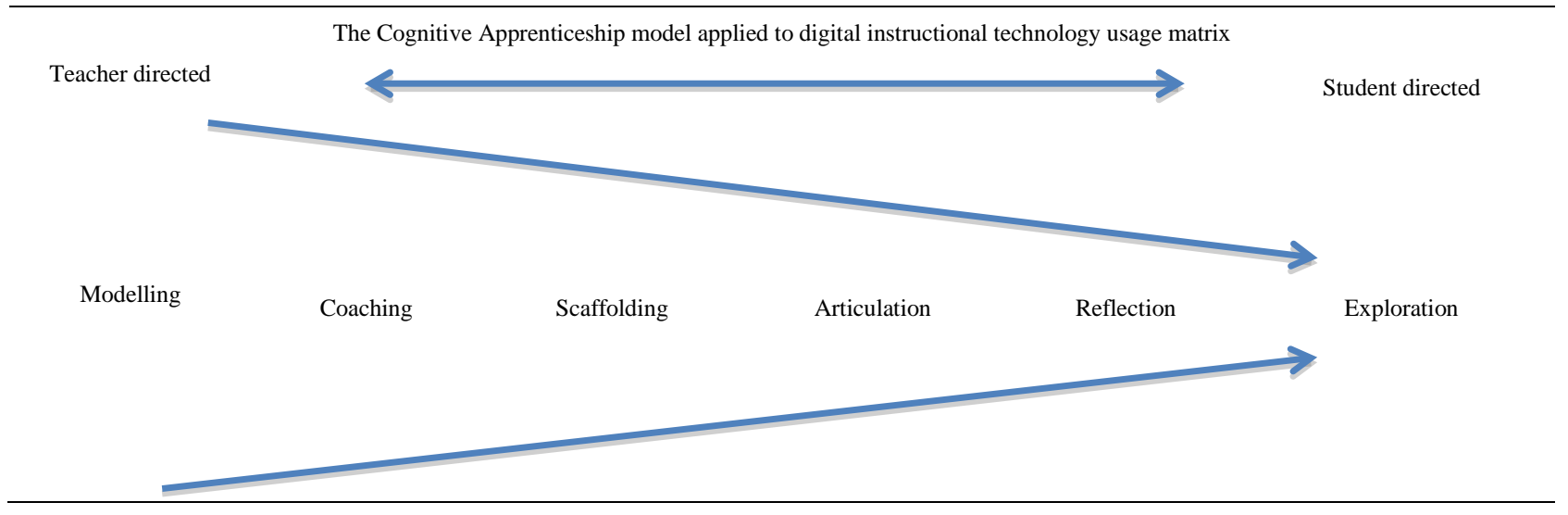

Table 3.

Three stages of learning from cognitive to associate to autonomous cognition.

\begin{tabular}{|c|c|c|c|c|c|}
\hline \multicolumn{6}{|c|}{ The Cognitive Apprenticeship model applied to digital instructional technology usage matrix } \\
\hline Modelling & Coaching & Scaffolding & Articulation & Reflection & Exploration \\
\hline Skype & Facebook & Blogs & $\begin{array}{c}\text { Virtual learning } \\
\text { environment: Collaborate }\end{array}$ & Blogs & $\begin{array}{l}\text { Personal learning } \\
\text { networks }\end{array}$ \\
\hline $\begin{array}{l}\text { Personal learning } \\
\text { networks }\end{array}$ & Wikis & Wikis & $\begin{array}{l}\text { Social networking } \\
\text { in Education }\end{array}$ & $\begin{array}{l}\text { Personal learning } \\
\text { networks }\end{array}$ & $\begin{array}{l}\text { Social networking } \\
\text { in Education }\end{array}$ \\
\hline Google docs & Skype & Skype & Personal learning networks & $\begin{array}{l}\text { Social networking } \\
\text { in Education }\end{array}$ & Google docs \\
\hline Lecture capture & $\begin{array}{l}\text { Personal learning } \\
\text { networks }\end{array}$ & $\begin{array}{l}\text { Personal learning } \\
\text { networks }\end{array}$ & Digital portfolios & Google docs & Flipped classroom \\
\hline $\begin{array}{l}\text { Social networking } \\
\text { in Education }\end{array}$ & $\begin{array}{l}\text { Social networking } \\
\text { in Education }\end{array}$ & $\begin{array}{l}\text { Social networking } \\
\text { in Education }\end{array}$ & Twitter & Twitter & Twitter \\
\hline Podcast & Lecture capture & $\begin{array}{l}\text { Virtual learning } \\
\text { environment: Collaborate }\end{array}$ & & & \\
\hline Vodcast & $\begin{array}{c}\text { Virtual learning } \\
\text { environment: Collaborate }\end{array}$ & Podcast & & & \\
\hline \multirow[t]{2}{*}{$\begin{array}{l}\text { Virtual learning } \\
\text { environment: Collaborate }\end{array}$} & Podcast & Twitter & & & \\
\hline & Vodcast & JPoll & & & \\
\hline \multicolumn{2}{|c|}{ The cognitive stage } & \multicolumn{2}{|c|}{ The associative stage } & \multicolumn{2}{|c|}{ The autonomous stage } \\
\hline
\end{tabular}


technology, the pedagogy experienced in these sessions did not necessarily assist in employing the technology in a range of learning contexts. To offer more support to staff, professional development would include discussions of problems that can and have emerged when employing the specific digital technologies and how to overcome them. While it is acknowledged that students have to access a variety of digital technologies in order to complete their courses successfully, our research provides evidence that explicitly teaching students the benefits of these technologies and explaining different ways that students can utilise these tools for learning will ensure better course delivery and outcomes.

Our results also indicate that in reality both the teaching and learning involved in utilising new digital technologies are not static and instead may shift between processes and stages in a dynamic way depending on the experience, motivation and disposition of the teacher and the learner. To help both university teaching staff and students understand how to cater for the diverse learning styles and experience in using digital technologies, a modified Cognitive Apprenticeship Model was developed. What makes the model useful is its ability to associate the most appropriate instructional delivery technology with the cognitive stage of the learner. By addressing both the needs and goals of the users, and the features of the technology, this model speaks to the factors that influence technology-task fit. Promoting awareness and understanding of the relationship between the technology and the needs and goals of its user(s) is essential to increasing engagement and satisfaction.

\section{REFERENCES}

Arbaugh, J. B. (2008). Does the community of inquiry framework predict outcomes in online MBA courses? International Review of Research in Open and Distance Learning, 9.

http://www.irrodl.org/index.php/irrodl/article/viewArticle/490/1045

Boston, W., Diaz, S. R., Gibson, A. M., Ice, P., Richardson, J., \& Swan, K. (2009). An exploration of the relationship between indicators of the Community of Inquiry framework and retention in online programs. Journal of Asynchronous Learning Networks, 13, 67-83.

Brown, A. L. (1992). Design experiments: Theoretical and methodological challenges in creating complex interventions in classroom settings. Journal of the Learning Sciences, 2, 141-178. http://dx.doi.org/10.1207/s15327809jls0202_2

Brown, A. L., \& Campione, J. C. (1996). Psychological theory and the design of innovative learning environments: On procedures, principles, and systems. In R. Glaser (Ed.), Innovations in learning: New environments for education (pp. 289-325). Mahwah, NJ: Erlbaum.

Brown, J. S., Collins, A., \& Duguid, P. (1989). Situated cognition and the culture of learning. Educational Researcher, 18, 32-41. http://dx.doi.org/10.3102/0013189X018001032

Collins, A. (1992). Toward a design science of education. In E. Scanlon, \& T. O'Shea (Eds.), New directions in educational technology (pp. 15-22). New York: Springer-Verlag. http://dx.doi.org/10.1007/978-3-642-77750-9_2

Collins, A., Brown, J. S., \& Newman, S. E. (1990). Cognitive apprenticeship: Teaching the crafts of reading, writing, and mathematics. In L. B. Resnick (Ed.), Knowing, learning, and instruction: Essays in honor of Robert Glaser (pp. 453-494). Hillsdale, NJ: Lawrence Erlbaum.

Felder, R. M. \& Brent, R. (2005). Understanding student differences. Journal of Engineering Education, 94, 57-72. http://dx.doi.org/10.1002/j.2168-9830.2005.tb00829.x

Garrison, D. R., \& Arbaugh, J. B. (2007). Researching the community of inquiry framework: Review, issues, and future directions. Internet and Higher Education, 10, 157-172. http://dx.doi.org/10.1016/j.iheduc.2007.04.001

Garrison, D. R., \& Cleveland-Innes, M. (2005). Facilitating cognitive presence in online learning: Interaction is not enough. American Journal of Distance Education, 19, 133-148.

http://dx.doi.org/10.1207/s15389286ajde1903_2

Goodhue, D., \& Thompson, R. L. (1995). Task-technology fit and individual performance. MIS Quarterly, 19, 213-236. http://dx.doi.org/10.2307/249689

Levy, Y. (2008). An empirical development of critical value factors (CVF) of online learning activities: An application of activity theory and cognitive value theory. Computers \& Education, 51, 1664-1675. http://dx.doi.org/10.1016/j.compedu.2008.04.003

Liaw, S. (2008). Investigating students' perceived satisfaction, behavioral intention, and effectiveness of e-learning: A case study of the Blackboard system. Computers \& Education, 51, 864-873. http://dx.doi.org/10.1016/j.compedu.2007.09.005

McGill, J., \& Klobas, J. E. (2009). A task-technology fit view of learning management system impact. Computers \& Education, 52, 496508. http://dx.doi.org/10.1016/j.compedu.2008.10.002

Moosmayer, D. C., \& Siems, F. U. (2012). Values education and student satisfaction: German business students' perceptions of universities' value influences. Journal of Marketing for Higher Education, 22, 257-272. http://dx.doi.org/10.1080/08841241.2012.746254

Richardson, J., \& Swan, K. (2003). Examining social presence in online courses in relation to students' perceived learning and satisfaction. Journal of Asynchronous Learning Networks, 7, 68-88.

Rubin, B., Fernandes, R., \& Avgerinou, M. D. (2013). The effects of technology on the Community of Inquiry and satisfaction with online courses. Internet and Higher Education, 17, 48-57. http://dx.doi.org/10.1016/j.iheduc.2012.09.006

Selim, H. M. (2007). Critical success factors for e-learning acceptance: Confirmatory factor models. Computers \& Education, 49, 396-413. http://dx.doi.org/10.1016/j.compedu.2005.09.004

Seymour, E., \& Hewitt, M. N. (1997). Talking about Leaving: Why Under-graduates leave the Sciences. Boulder, CO, Oxford: Westview Press.

Swan, K. (2002). Building learning communities in online courses: The importance of interaction. Education, Communication \& Information, 2, 23-49. http://dx.doi.org/10.1080/1463631022000005016

The Design-Based Research Collective (2003). Design-based research: An emerging paradigm for educational inquiry. Educational Researcher, 32, 5-8. http://dx.doi.org/10.3102/0013189X032001005

Worthen, B. R., Sanders, J. R., \& Fitzpatrick, J. L. (1996). Program evaluation: Alternative approaches and practical guidelines (2nd ed.). New York: Longman. 